\title{
Aerosol optical thickness (AOT) retrieval over land using satellite image-based algorithm
}

\author{
Diofantos G. Hadjimitsis
}

Received: 28 December 2008 / Accepted: 11 March 2009 / Published online: 25 March 2009

(C) The Author(s) 2009. This article is published with open access at Springerlink.com

\begin{abstract}
The aim of this study is to present and apply the proposed algorithm on archived time series Landsat TM over an urban area in the vicinity of Heathrow Airport (UK) acquired in 1984-1986 and to two up-to-dated Landsat TM images in the vicinity of Paphos Airport in Cyprus acquired in July-August 2008. The monitoring of aerosol concentrations becomes a high environmental priority particularly in urban areas. The proposed algorithm has been developed to allow the quantification of the aerosol optical thickness (AOT) over land. The algorithm compares multitemporal satellite data sets and evaluates radiometric alterations due to the optical atmospheric effects of aerosols. Novel features of this algorithm which is based on the application of radiative transfer calculations are the inclusion of applying iteration procedures for selecting the suitable object for determining the aerosol optical thickness and the automatic division into working grid cells. AOT retrieval from Landsat TM band 1 images of Cyprus has been crossvalidated satisfactorily by comparing AOT values found from handheld MICROTOPS II sun photometer.
\end{abstract}

Keywords Aerosoloptical thickness - Air pollution - Landsat $\mathrm{TM} / \mathrm{ETM}+\cdot$ Sun photometer

\section{Introduction}

A complex mixture of organic and inorganic particles (aerosols) can be found suspended in the atmosphere in

D. G. Hadjimitsis $(\bowtie)$

Department of Civil Engineering and Geomatics,

Cyprus University of Technology,

P.O. Box 50329, 3036 Lemesos, Cyprus

e-mail: d.hadjimitsis@cut.ac.cy solid, liquid, or both physical states (Gupta et al. 2006). The presence of non-natural origin is linked to important climatic and environmental effects. It has been shown that there are strong interactions of these particles with the solar radiation, the Earth, and the atmospheric gases, which can affect significantly the atmospheric physical and chemical characteristics, the temperature vertical profile, and other thermodynamic variables, as well as the Earth surface characteristics and its temperature (Leon et al. 1995, 2001; Ortore and Francione 2008).

Aerosols are considered as the most important parameter for the following reasons: (a) The effects of aerosols represent one of the largest uncertainties in predicted climate change (Haywood and Boucher 2000). (b) Effective aerosol retrieval information is also essential to satellite imagery atmospheric correction (Kaufman and Tanré 1996; Kaufman and Sendra 1998; Hadjimitsis et al. 2004; Hadjimitsis 2008). (c) Aerosols are considered as one of the major air pollutants responsible for human health problems related to the respiratory system. Studies on the particles have demonstrated the existence of a link between the presence of fine and ultrafine particulate of non-natural origin and some effects on the health of human and other living beings especially due to industrial and urban emissions which are a major source of aerosols (Leon et al. 1995, 2001; Ortore and and Francione 2008).

The suspension and transport potential of aerosols as well as its relationship with $\mathrm{SO}_{2}$ and $\mathrm{NO}_{2}$ makes aerosols a good indicator of air pollution at urban and regional scales thus emphasizing the importance of developments in satellite aerosol retrieval. The study of aerosols or any other atmospheric pollutant dispersion patterns relies on spatial and temporal data series obtained from air quality monitoring networks or measurement campaigns (Al-Saadi et al. 2005). Such monitoring programs entail a high implementation and 
maintenance costs and are limited in terms of spatial coverage. The measuring stations are scarcely distributed, and they do not provide sufficient tools for mapping atmospheric pollution, since air quality is highly variable (Wald et al. 1999). However, earth observations made by satellite sensors are certainly a valuable tool for assessing and mapping atmospheric pollution due to their major benefit of providing complete and synoptic views of large areas in one snapshot (Hadjimitsis et al. 2002). Indeed, the integration of statistical and physical modeling and introduction of a wide range of satellite sensors (such as ATSR-2 radiometer on board the ESA satellite ERS-2, POLDER on the ADEOS spacecraft, and MISR on TERRA, etc.) can overcome such limitations (Tang et al. 2005). Satellite imagery can be used to better assess the spatial structure of air pollution and interactions on global, regional, or local dispersion pattern (Tang et al. 2005). The determination of aerosol optical thickness (AOT) from satellite image data can be used as a tool for assessing air pollution in any area of interest (Sifakis and Deschamps 1992; Sifakis et al 1998; Hadjimitsis and Clayton 2006; Leon et al. 1995).

AOT retrieval is validated by comparing with groundbased or handheld sun photometer measurements. The Aerosol Robotic Network (AERONET), which is an example of ground-based systems, is a worldwide network of automatic sun photometers and data archive, providing spectral aerosol optical thickness as well as aerosol microphysical properties (Holben et al. 1998; Tang et al. 2005).

The present approaches for remote sensing of aerosol over land can be grouped into the following four fully image-based processing techniques: the "ocean method," "brightness method," "contrast-reduction method," and the "Dark vegetation" (Teillet and Fedosejevs 1995; Tulloch and Li 2004; Hadjimitsis and Clayton 2006). Such approaches can be found as a step in several atmospheric correction algorithms intended to remove atmospheric effects from satellite remotely sensed data. In the atmospheric correction of the remotely sensed earth image data, we need the information on the aerosol optical parameters. Since simultaneous measurements of the aerosol optical thickness are not always possible, a method for estimating it from the satellitemeasured data itself is highly desirable. In this study, we applied a fully image-based method to Landsat-5 and $7 \mathrm{TM} /$ $\mathrm{ETM}+$ band 1 data for determining the aerosol optical thickness. The method consists of the following novel features: the "iterative tool" and the automatic division of the scene into grid cells (depending of the presence of dark targets).

\section{Atmospheric correction of satellite imagery}

Radiation from the earth's surface undergoes significant interaction with the atmosphere before it reaches the satellite sensor. Any sensor that records electromagnetic radiation from the earth's surface using visible or nearvisible radiation will typically record a mixture of two kinds of radiance or reflectance. The value recorded at any pixel location on a remotely sensed image does not represent the true ground-leaving radiance at that point. Part of the brightness (radiance or reflectance) is due to the reflectance of the target of interest, and the remainder is derived from the brightness of the atmosphere itself. The separation of contributions is not known a priori, so the objective of atmospheric correction is to quantify these two components so that the main analysis can be made on the correct target reflectance or radiance values (Hadjimitsis 1999). After the remotely sensed data have been received and undergone preliminary correction at the groundreceiving station, the next step is to pre-process the data. Pre-processing refers to those operations that precede the main image analysis, and include geometric and radiometric corrections. Radiometric correction is more difficult than correction for geometric effects, since the distributions and intensities of these effects are often inadequately known; but unfortunately, it cannot be neglected, particularly when multitemporal images are to be interpreted (Hadjimitsis et al. 2004; Richards and Jia 2005). The most difficult step in radiometric correction is the removal of atmospheric effects. The basis of any correction of a satellite image is to identify and understand the process which contaminates the satellite image. In the case of atmospheric effects, the origin for any attempt to perform atmospheric correction to satellite data is the setting up of an equation (Turner and Spencer 1972), which describes all the processes with the various atmospheric parameters and variables, which contribute to the attenuation of the signal received by a satellite sensor. This equation is called the radiative transfer (RT) equation. The processes described in such an equation are the scattering and absorption by atmospheric gases, aerosol, and clouds of the electromagnetic radiation.

The significant problem in the atmospheric correction of remotely sensed data is the difficulty of obtaining accurate values for those parameters described in the radiative transfer equation (Kaufman and Sendra 1988) or the limited availability of the atmospheric correction parameters in the analysis of most images (Duggin and Robinove 1990). The basic philosophy of atmospheric correction is to determine the optical characteristics of the atmosphere and then to apply this to correct the satellite image data. Taking into consideration that the atmospheric effects are mainly caused by scattering and absorption of atmospheric gases, aerosol, and clouds, the most important point in order to perform an atmospheric correction is to be aware of the optical characteristics of the atmosphere. These optical characteristics can be found from different sources such as the general 
climatology of the area under investigation (Kneizys et al. 1983), the image itself (Gordon et al. 1983), or ground measurements (Kaufman and Fraser 1983). Molecular scattering and absorption are not considered to vary in time and space. Nevertheless, aerosol scattering and absorption do vary, and these are the main variables in the atmospheric effect on satellite remote sensing. One way to describe the information which refers to the atmospheric optical characteristics is by using the four following parameters: the aerosol optical thickness, the phase function (the angular distribution of the scattered radiation, which is the probability that light will be scattered into a unit solid angle), the single scattering albedo, and the gaseous absorption (Hadjimitsis 1999). The main problem in atmospheric correction is the difficulty in determining these optical characteristics and especially the aerosol optical thickness which is the most important unknown parameter for every atmospheric correction algorithm or air-quality model. The problem of atmospheric intervention has received considerable attention from researchers in remote sensing who have developed a range of methods, both simple and sophisticated. Hadjimitsis et al. (2004) categorizes the atmospheric correction algorithms into absolute and relative corrections and explored the need to develop fully image-based atmospheric correction methods.

\section{The principle of darkest pixel atmospheric correction}

One of the most widely used and well-known simple atmospheric correction methods, which are based only on the image itself, is the darkest pixel (DP) method. It is also termed the histogram minimum method, the darkest object subtraction method, and the dark target approach (Hadjimitsis et al. 2003). The DP may correspond to a large water body or other dark object or feature within the image. The principle of the DP approach is that most of the signal reaching a satellite sensor from a dark object is contributed by the atmosphere at visible wavelengths (Hadjimitsis et al. 2003). Therefore, the pixels from dark targets are indicators of the amount of upwelling path radiance in that band. The atmospheric path radiance adds to the surface radiance of the dark target, giving the target radiance at the sensor. The surface radiance of the dark target is approximated as having zero surface radiance or reflectance. Another adaptation of the DP method is to assume a known nonzero surface reflectance of the dark target (Teillet and Fedosejevs 1995; Hadjimitsis and Clayton 2008). The main characteristic of dark objects is the very-near-zero radiance in the infrared spectrum. This is due to the fact that water absorbs strongly in the near-infrared, and any scattering effect is negligible. The method was first developed to correct only for the additive scattering effect (Hadjimitsis et al. 2003). The darkest pixel technique assumes that there is a high probability that there are at least a few pixels in the image with very low reflectivity, which is assumed to correspond to black surface with $0 \%$ reflectance. The assumption that there are few pixels in the image with near zero reflectance is based on the fact that, in a single band, there very large numbers of pixels, and the probability to find a dark pixel is very high (Chavez 1988).

The need to develop image-based and operationally simple and fast processing atmospheric correction algorithms has led a number of researchers to make use of targets whose ground reflectances do not change significantly with the time, i.e., pseudo-invariant targets (Hadjimitsis et al. 2009). Then, by using a variety of atmospheric correction methods either darkest pixel approach or empirical line normalization method or other methods, the aerosol optical thickness can be determined. In order to quantify the aerosol amount and their concentration variation, it is necessary to select and consider "dark targets" characterized by spectral signatures as much constant and well known as possible. To take into account a "dark pixel" (low reflectance) does not mean that it is possible to exclude the surface contribution, which can be time-varying in accordance with the corresponding changes of surface characteristics. In the case where a "dark pixel" is characterized by a not negligible reflectance, it is necessary to examine and evaluate the possible surface reflectance variations when an image temporal series is considered. This has been already examined using ground spectro-radiometric measurements for several different types of dark targets such as asphalt surfaces or water treatment reservoirs. The method needs considerable care when the dark target is water, since trophic state reflectance values have been found to be changed in the 0.52 - to $0.70-\mu \mathrm{m}$ spectral region. In such case, the aerosol optical thickness takes values with nearly $10 \%$ difference. Indeed, the proposed method can be more efficiently applied to nonvariant dark targets.

\section{Methodology}

The method is based on the fact that any changes between the derived atmospheric path radiances can be attributed to varying degrees of scattering and absorption by varying concentrations of aerosols (including haze), since molecular scattering is assumed to be constant with time in the same geographical area.

The proposed methodology is shown in Fig. 1 and is described below:

- Apply geometric correction.

- It is recommended to divide the image under investigation into different subregions. This is more important 
Fig. 1 Methodology description

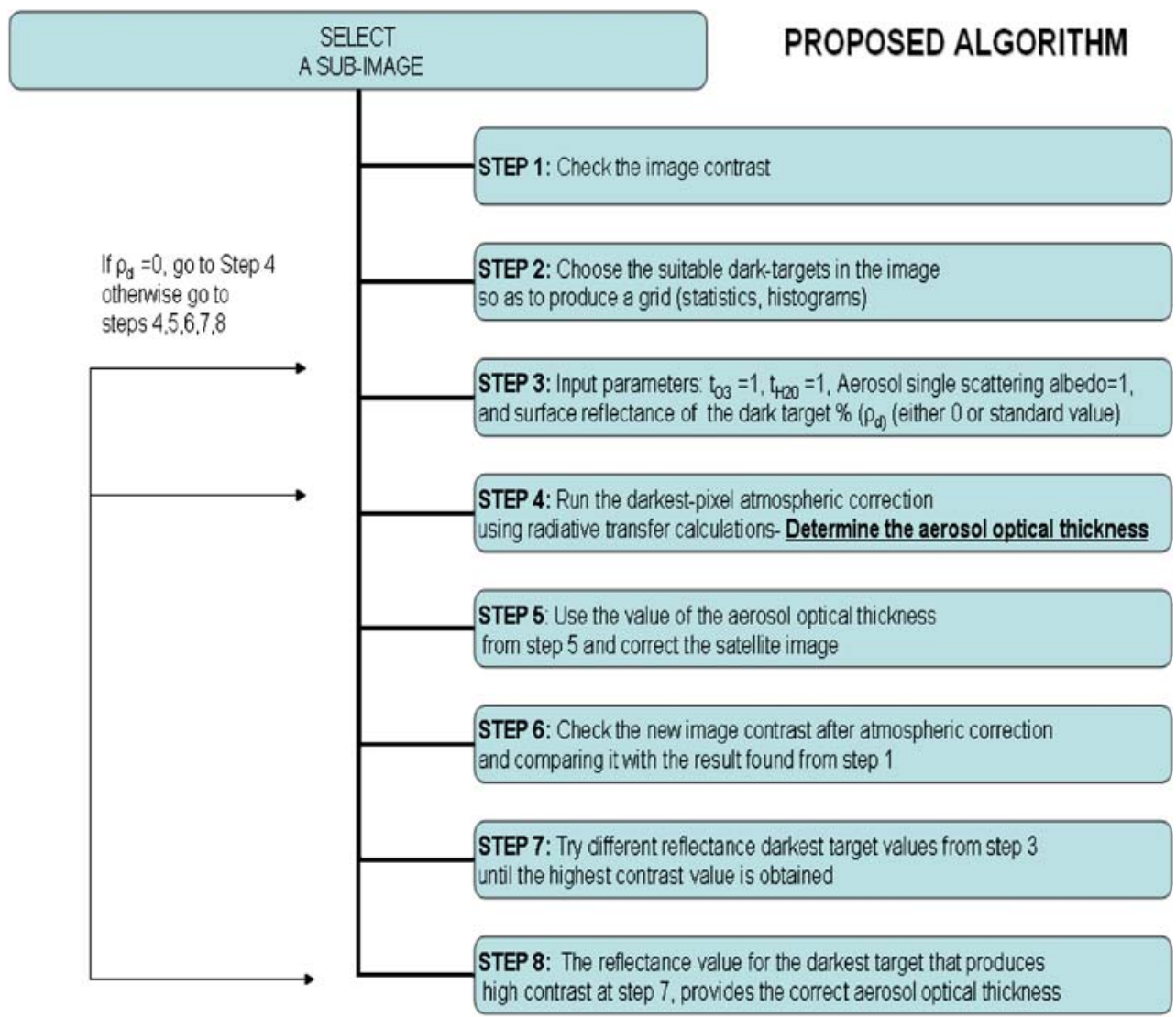

for hazy atmospheres with spatial variability. The algorithm based on Euclidean distance tool (ERDAS 2008) decides automatically the type of the grid cells (i.e., the dimensions).

- Check the image contrast.

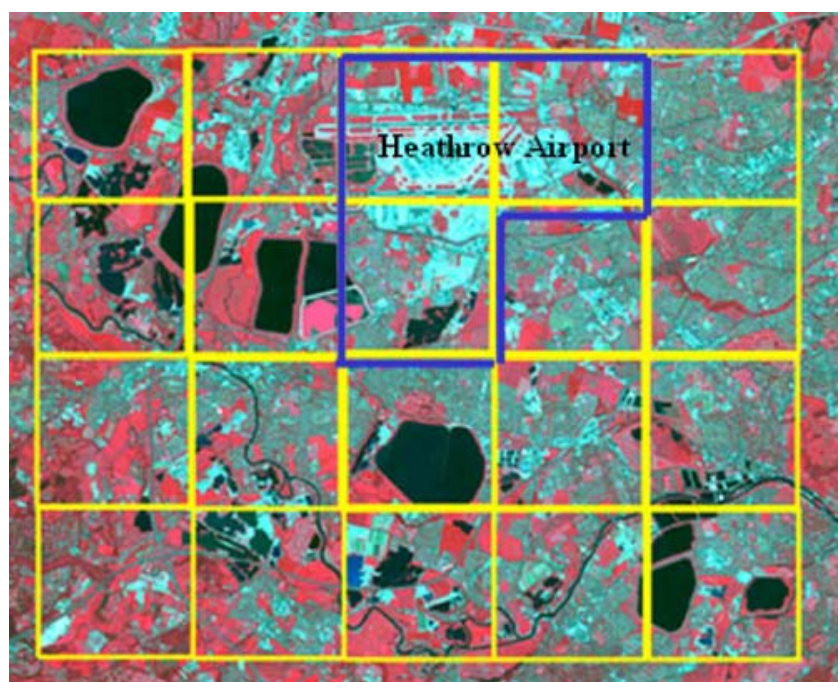

Fig. 2 Illustration of the Landsat-5 TM image (2 June 1985) of the West London (partial scene: vicinity of Heathrow Airport). The algorithm requires the division of the image to grid cells
- By applying the principle of the DP method, every dark pixel in the subregion represents the atmospheric path radiance in this region. The atmospheric path radiance is a function of total optical thickness which is the term used to define the prevailing atmospheric conditions.

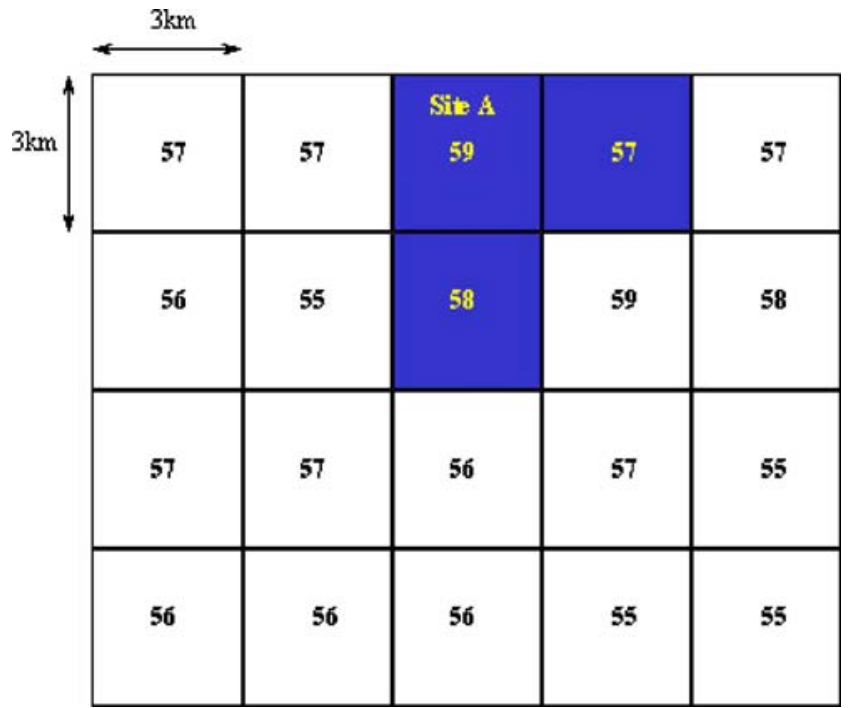

Fig. 3 Illustration of the grid cells of $3 \mathrm{~km} \times 3 \mathrm{~km}$ 
Fig. 4 Mapping in contour lines of the atmospheric path radiance (consisting of Rayleigh optical thickness and aerosol optical thickness). It is apparent that the high values of the atmospheric path radiance correspond to the area near the Heathrow Airport

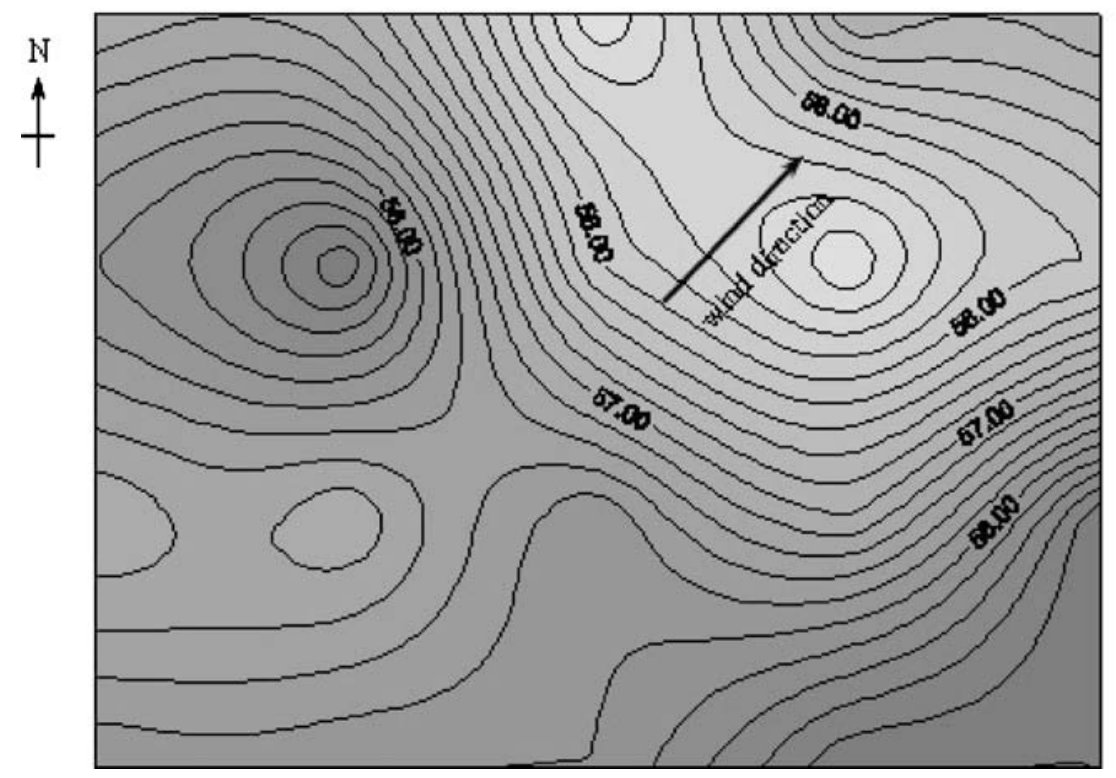

(b)

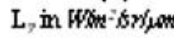

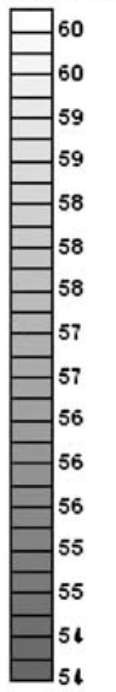

- Rayleigh scattering is considered to be constant with time in the same geographical area in all the images. Ozone has a variable but minor effect. Water vapor effects are assumed to be constant through the limited interval of the images (based also on the available relative humidity). The reason that the Landsat TM band 1 is used is to minimize the effect of water vapor absorption. If these conditions are met, then any significant variations of atmospheric path radiance between

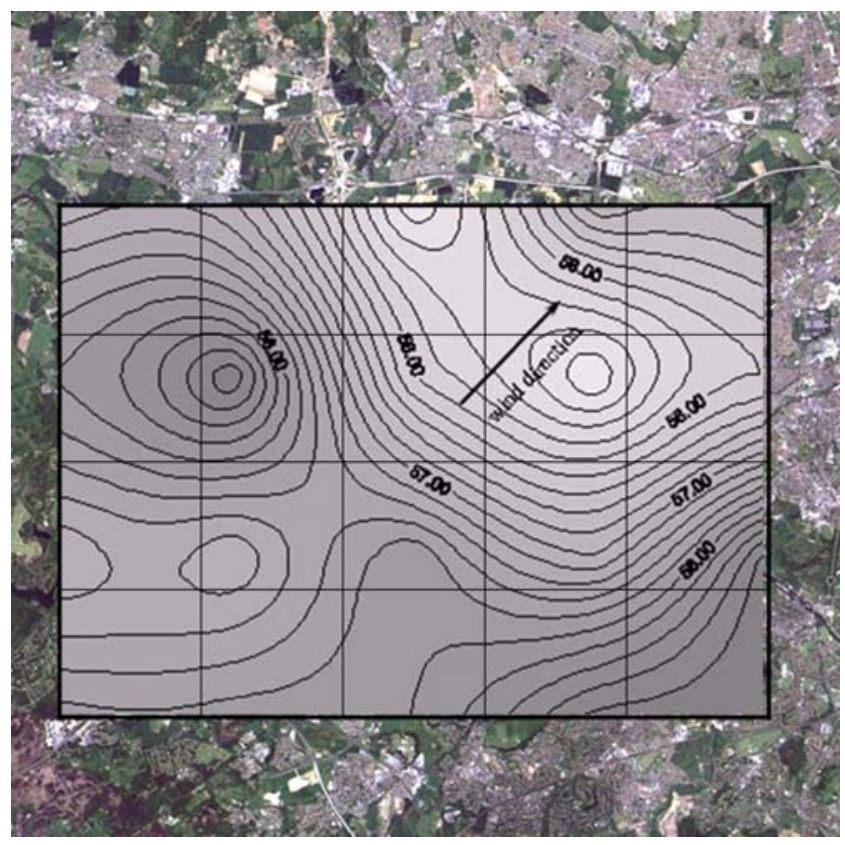

Fig. 5 An overlay of the "atmospheric-path component" contour map over the grid and image area the images will be due to changes in the distribution and changes in concentrations of aerosols. Input parameters are ozone transmittance $\left(t_{\mathrm{O} 3}\right)=1$, water vapor transmittance $\left(t_{\mathrm{H} 20}\right)=1$, aerosol single scattering albedo $=1$ (perfectly scattering aerosol), surface reflectance of the dark-target: use standard values (from spectral library files or consider it as zero value).

- Run the iterative tool. Use maximum number of ten iterations. Then during each iteration, aerosol optical thickness is recalculated, and all pixels are corrected with respect to the new aerosol optical thickness. This routine will continue to refine the atmospheric correction iteratively until the images reaches the maximum contrast value.

- Determine the atmospheric path radiance (first indication of the atmospheric pollution) and provide a contour map.

- Run the radiative transfer calculations (Turner and Spencer 1972), and determine the aerosol optical thickness.

Table 1 Calculated aerosol optical thickness for the site A-Heathrow Airport area

\begin{tabular}{ll}
\hline Image date & Calculated aerosol optical thickness \\
\hline 12 April 1984 & 0.40 \\
5 March 1985 & 0.31 \\
2 June 1985 & 0.13 \\
29 September 1985 & 0.60 \\
8 March 1986 & 0.55 \\
28 June 1986 & 0.70 \\
\hline
\end{tabular}




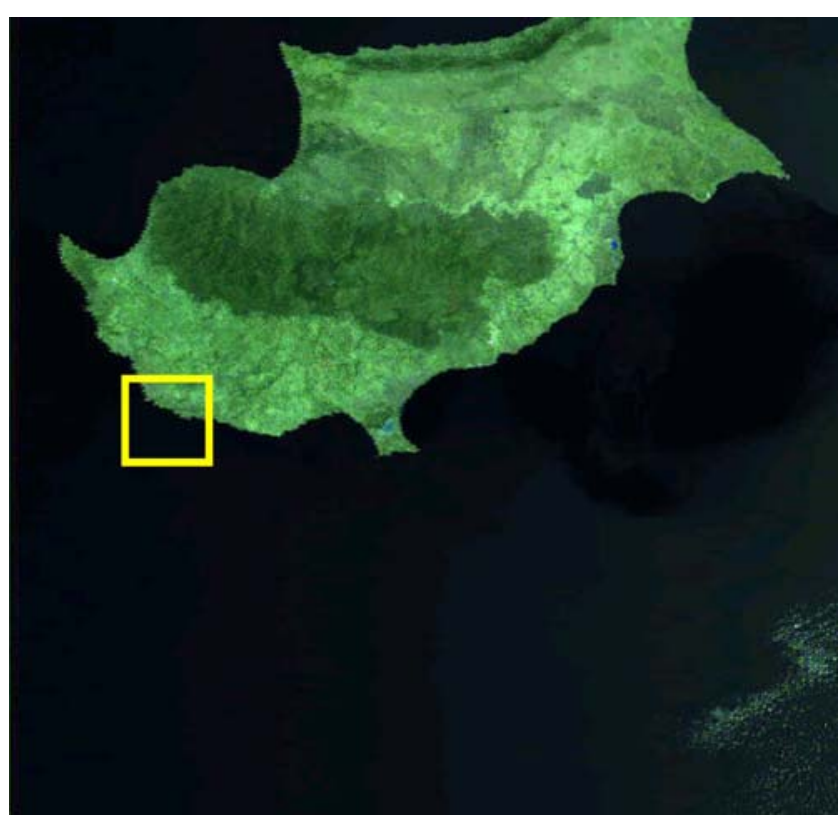

Fig. 6 Landsat-5 TM image of Cyprus (20 July 2008). Area of interest is marked

\section{Results}

The proposed method has been tested in two different geographical areas: the London Heathrow Airport area (UK) and to areas in the vicinity of Paphos Airport area in Cyprus.

\section{London Heathrow Airport area (UK)}

The method has been applied in an area near the Heathrow Airport in West London consisting of many inland water bodies such as lakes and reservoirs as shown in Fig. 2. Figure 3 shows the automatic definition of the grid cells based on the availability of dark targets, and Fig. 4 shows the production of contour map for the determined atmospheric path radiances. Each value of atmospheric path

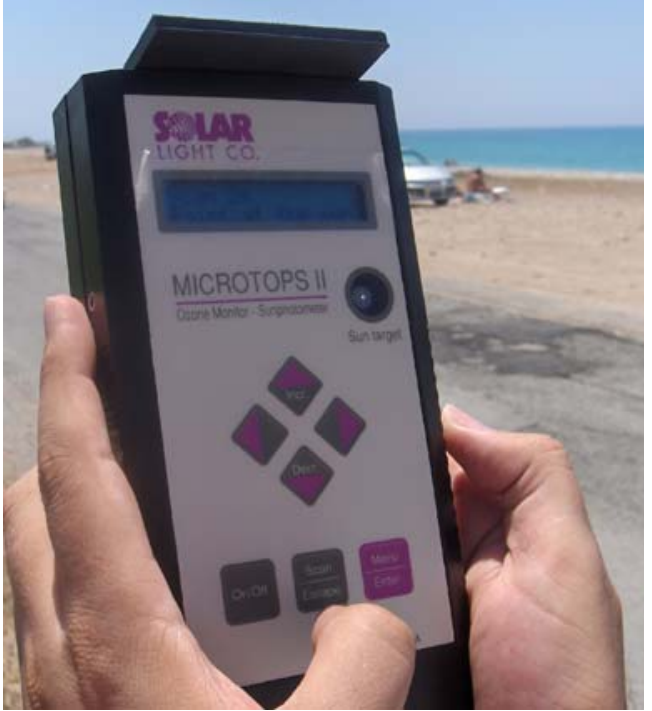

Fig. 8 Sun photometer measurements

radiance corresponds to different values of aerosol optical thickness. An overlay of the contour map over the grid and image area is shown in Fig. 5.

The method has been applied to a series of Landsat-5 TM images, and the obtained aerosol optical thickness for site A (see Fig. 3) are shown in Table 1.

From the derived aerosol optical thickness of every image shown in Table 1, it can be concluded that the most atmospheric polluted images due to particulate were the 29 September 1985 and 28 June 1986, and the less polluted were the 2 June 1985 and 5 March 1985 images. For the images acquired on 2 June 1985 and 28 June 1896, the acquired visibility values during the satellite overpass were 26.2 and $5.4 \mathrm{~km}$, respectively (Hadjimitsis and Clayton 2008). This is another supportive tool for the determined aerosol optical thickness values. Visibility is closely related to the aerosol optical thickness as shown by Forster (1984), Tanre et al. (1987), and Hadjimitsis and Clayton (2006).
Fig. 7 Subset image of Fig. 5. Paphos Airport Area Landsat-5

TM image acquired on 20 July 2008

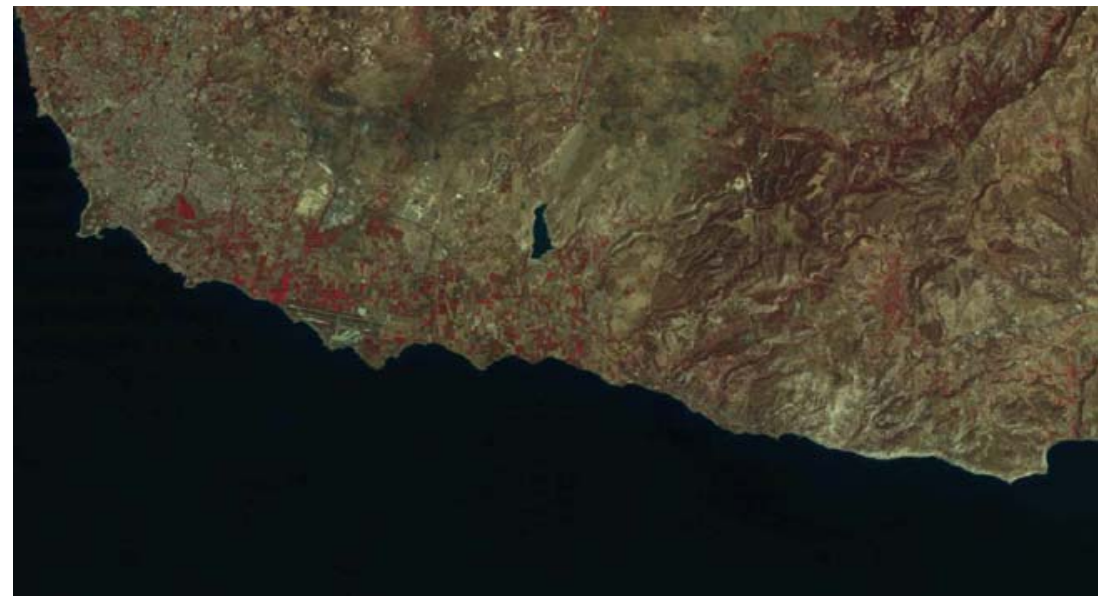


Table 2 Calculated aerosol optical thickness from the Landsat TM band 1 images and sun photometer for the area very close to the Paphos Airport

\begin{tabular}{|c|c|c|c|c|}
\hline Image date & $\begin{array}{l}\text { AOT obtained from sun } \\
\text { photometer (at } 500 \mathrm{~nm} \text { ) }\end{array}$ & AOT Landsat TM band 1 & $\begin{array}{l}\text { Visibility }(\mathrm{km}) \text { at } \\
\text { Paphos Airport }\end{array}$ & RH (\%) \\
\hline 20 July 2008 & 0.124 & 0.130 & 9:00 AM: 70 & 9:00 AM: 70 \\
\hline Landsat-5 TM & & & 10:00 Ам: 70 & 10:00 AM: 77 \\
\hline 13 August 2008 & 0.380 & 0.370 & 9:00 AM: 62 & 9:00 AM: 71 \\
\hline Landsat-7 ETM+ & & & 10:00 АM: 60 & 10:00 AM: 72 \\
\hline
\end{tabular}

Paphos Airport-Cyprus

The proposed method has been applied to Landsat TM/ ETM+ image data of the Paphos District area in Cyprus, acquired on the 20th of July 2008 (see Figs. 6 and 7) and 13th of August 2008. The Microtops II (Solar Light Company, USA) handheld sun photometer (see Fig. 8) that provides aerosol optical thickness (AOT) from instantaneous measurements, at five channels $(440,500,670$, 936, and $1020 \mathrm{~nm}$ ) was used in this study to determine the aerosol optical thickness. An average value of the aerosol optical thickness determined using the sun photometer between 9.00 and 11.00 A.M. was used. The Landsat satellite overpass was between 9.20 and 9.30 A.M.

By comparing the aerosol optical thickness obtained using the proposed method and those found using the sun photometer, it is apparent that there is a much closed agreement between the two (see Table 2). It is apparent that for the image acquired on the 20th of July 2008, a high visibility value has been found. This provides evidence of a less polluted image date than the one observed on the 13th of August 2008. Relative humidity (RH) for both dates is within the same ranges, so any water vapor effect is negligible especially when short wavelengths are used (Hadjimitsis and Clayton 2008).

\section{Conclusions}

This study shows how the proposed algorithm with the two new novel options, the iterative and the automatic division of an image into grid cells can be used to assess the spatial and temporal variability of the aerosol optical thickness. Such method can be useful for the management of air pollution stations and for improvement of the local air pollution network for urban areas, since the production of such path radiances and aerosol optical thickness maps can be useful for an assessment of the existing network.

The proposed algorithm has been applied on archived time series Landsat TM over an urban area in the vicinity of Heathrow Airport (UK) and to two up-to-dated Landsat TM images in the vicinity of Paphos Airport in Cyprus. AOT retrieval from Landsat TM/ETM+ band 1 images of Cyprus has been cross-validated satisfactorily by comparing AOT values found from handheld MICROTOPS II sun photometer. Visibility values acquired during the satellite overpass for both case studies support the aerosol optical thickness assessment.

The method may need several improvements in the near future, since some algorithm limitations must be reexamined such as the initial determination of the contrast value and the insertion of assumed values for the atmospheric parameters. The assumption of the existence of perfectly scattered aerosols needs further investigation.

It is important to highlight that Landsat TM-5 is a very old sensor, and Landsat ETM+ has severe acquisition problems. Moreover, there are no plans to replace these sensors in the next few years. Indeed, ASTER satellite sensor is a promising one and has been already used by several other researchers. Indeed, the author suggest that the method can be applied to advanced spaceborne thermal emission and reflection radiometer (ASTER; 0.52-60 $\mu \mathrm{m}$ ) only when in situ reflectance values of the selected dark targets are available. Future work consists of further extending the proposed method to ASTER image data.

Further validation is needed to support our proposed algorithm using simultaneous acquisition of the following data: air pollution data, meteorological data, sun-photometer data, and satellite image data. The proposed algorithm will be further tested using the ground-based sun-photometer system which will provide spectral aerosol optical thickness as well as aerosol microphysical properties. Due to their relatively high accuracy (AOT uncertainty $< \pm 0.01$ at wavelengths $>$ $440 \mathrm{~nm}$ ), AERONET data have been widely used as a standard for validating satellite aerosol retrievals as shown by Dubovik et al. (2000). A Sun-photometer ground system similar to those used for AERONET project is expected to be installed at the Cyprus University of Technology in the near future for further validation.

Acknowledgements The author wish to acknowledge a grant from the Cyprus University of Technology for supporting this study. Thanks are also given to the Remote Sensing Laboratory of the Department o Civil Engineering and Geomatics (Cyprus University of Technology) (http://www.cut.ac.cy) for the provision of the Microtops 
II sunphotometers, GER1500 field spectro-radiometers and ERDAS Imagine Software.

Open Access This article is distributed under the terms of the Creative Commons Attribution Noncommercial License which permits any noncommercial use, distribution, and reproduction in any medium, provided the original author(s) and source are credited.

\section{References}

Al-Saadi J, Szykman J, Pierce RB, Kittaka C, Neil D, Chu DA, Remer L, Gumley L, Prins E, Weinstock L, Macdonald C, Wayland R, Dimmick F, Fishman J (2005) Improving national air quality forecasts with satellite aerosol observations. Bull Am Meteorol Soc 86(9):49-1261. doi:10.1175/BAMS-86-9-1249

Chavez PS (1988) An improved dark-object subtraction technique for atmospheric scattering correction of multi-spectral data. Remote Sens Environ 24:458-479

Dubovik O, Smirnov A, Holben BN, King MD, Kaufman YJ, Eck TF et al (2000) Accuracy assessments of aerosol optical properties retrieved from Aerosol Robotic Network (AERONET) Sun and sky radiance measurements. Journal of Geophysical ResearchAtmospheres 105(D8):9791-9806. doi:10.1029/2000JD900040

Duggin MJ, Robinove CJ (1990) Assumptions implicit in remote sensing data acquisition and analysis. Int J Remote Sens 11 (10):1669-1694. doi:10.1080/01431169008955124

Erdas I (2008) Erdas IMAGINE-Tour guides. Ga., Erdas, Inc, Atlanta

Forster BC (1984) Derivation of atmospheric correction procedures for Landsat MSS with particular reference to urban data. Int J Remote Sens 5(5):799-817

Gordon HR, Clark DK, Brown JW, Evans RH, Broenkow WW (1983) Phytoplankton pigment concentrations in the Middle Atlantic Bight: Comparison of ship determinations and CZCS estimates. Appl Opt 22(1):20-36

Gupta P, Christopher SA, Wang J, Gehrig R, Lee YC, Kumar N (2006) Satellite remote sensing of particulate matter and air quality over global cities. Atmos Environ 40(30):5880-5892. doi:10.1016/j.atmosenv.2006.03.016

Hadjimitsis DG, Clayton CRI (2006) Detecting Air pollution from Space Using Image-based method', International Conference: Protection and Restoration of the Environment VIII, Crete, July, 2006, organized by the: Technical University of Crete, Stevens Institute of Technology: 313

Hadjimitsis DG, Clayton CRI, Retalis A (2009) The use of selected pseudoinvariant targets for the application of atmospheric correction in multi-temporal studies using satellite remotely sensed imagery. International Journal of Applied Earth Observation and Geoinformation dx.doi.org/10.1016/j.jag.2009.01.005

Hadjimitsis DG, Clayton CRI, Retalis A (2003) Darkest pixel atmospheric correction algorithm: a revised procedure for environmental applications of satellite remotely sensed imagery, Proceedings 10th International Symposium on Remote Sensing, 8-12/9/2003, Barcelona-SPAIN, organized by NASA, SPIE CONFERENCE, and p.414

Hadjimitsis DG, Retalis A, Clayton CRI (2002) The assessment of atmospheric pollution using satellite remote sensing technology in large cities in the vicinity of airports. Water Air Soil Pollut Kluwer Acad Publishers 2(5-6):631-640

Hadjimitsis DG (2008) Description of a new method for retrieving the aerosol optical thickness from satellite remotely sensed imagery using the maximum contrast value principle and the darkest pixel approach. Trans GIS J 12(5):633-644. doi:10.1111/j.1467-9671. 2008.01121.x

Hadjimitsis DG, Clayton CRI (2008) The use of an improved atmospheric correction algorithm for removing atmospheric effects from remotely sensed images using an atmosphere-surface simulation and meteorological data. Meteorol Appl J 15(3): 381-387. doi:10.1002/met.80

Hadjimitsis DG (1999) The application of atmospheric correction algorithms in the satellite remote sensing of reservoirs. Ph.D. Thesis. University of Surrey, Department of Civil Engineering, Guildford, UK

Hadjimitsis DG, Clayton CRI, Hope VS (2004) An assessment of the effectiveness of atmospheric correction algorithms through the remote sensing of some reservoirs. Int J Remote Sens 25 (18):3651-3674. doi:10.1080/01431160310001647993

Haywood J, Boucher O (2000) Estimates of the direct and indirect radiative forcing due to tropospheric aerosols: a review. Rev Geophys 38:513-543. doi:10.1029/1999RG000078

Holben BN, Eck TF, Slutsker I, Tanre D, Buis JP, Setzer A et al (1998) AERONET - a federated instrument network and data archive for aerosol characterization. Remote Sens Environ 66(1):1-16. doi:10.1016/S0034-4257(98)00031-5

Kaufman YJ, Tanré D (1996) Direct and indirect methods for correcting the aerosol effect on remote sensing. Remote Sens Environ 55:65-79. doi:10.1016/0034-4257(95)00193-X

Kaufman YJ, Sendra C (1988) Algorithm for automatic atmospheric corrections to visible and near-IR satellite imagery. Int J Remote Sens 9(8):1357-1381. doi:10.1080/01431168808954942

Kaufman YJ, Fraser RS (1983) Light extinction by aerosols during summer air pollution. J Appl Meteorol 22:1694-1706. doi:10.1175/1520-0450(1983)022<1694:LEBADS >2.0.CO;2

Kneizys FX, Shettle EP, Gallexy WO, Chetwynd JH, Abreu LW, Selby JEA, Clough SA, Fenn RW (1983) Atmospheric transmittance/ Radiance: Computer Code LOWTRAN 6. Air Force Geophysics Laboratory, Hanscom Air Force Base, Massachusetts

Léon J, Chazette P, Dulac F (1995) Retrieval and monitoring of aerosol optical thickness over an urban area by spaceborne and ground-based remote sensing. Appl Opt 38(33):6918-6926. doi: 10.1364/AO.38.006918

Léon J-F, Chazette P, Dulac F, Pelon J, Bonnazola M, Foret G, Cautenet S, Cachier C, Alfaro SC, Gaudichet A, Gomes L, Rajot J-L, Lavenu F, Inamdar SR, Sarode PR (2001) Large scale advection of continental aerosols during INDOEX. J Geophys Res 106 D22, pp 28427-28439

Ortore E, Francione V (2008) On the aerosols monitoring by satellite observations. Clean Technol Environ Policy 10(2):137. doi:10.1007/s10098-007-0134-3

Richards J, Jia X (2005) Remote sensing digital image analysis: an introduction, fourthth edn. Springler-Verlag, Berlin

Sifakis N, Soulakellis N, Paronis D (1998) Quantitative mapping of air pollution density using Earth observations: a new processing method and application to an urban area. Int J Remote Sens 19 (17):3289-3300. doi:10.1080/014311698213975

Sifakis N, Deschamps PY (1992) Mapping of air pollution using spot satellite data. Photogramm Eng Remote Sensing 58:14331437

Tang J, Xue Y, Yu T, Guan Y (2005) Aerosol optical thickness determination by exploiting the synergy of TERRA and AQUA MODIS. Remote Sens Environ 94(3):327-334. doi:10.1016/j. rse.2004.09.013

Tanre D, Deschamps PY, Duhaut P, Herman M (1987) Adjacency effect produced by the atmospheric scattering in the Thematic Mapper data. J Geophys Res 92:12000-12006. doi:10.1029/ JD092iD10p12000 
Teillet PM, Fedosejevs G (1995) On the dark target approach to atmospheric correction of remotely sensed data. Can J Rem Sens 21(4):375-381

Tulloch M, Li J (2004) Applications of satellite remote sensing to urban air-quality monitoring: status and potential solutions to Canada. Environ Inform Arch 2:846-854

Turner RE, Spencer MM (1972) Atmospheric model for correction of spacecraft data. Proceedings of the eighth International Sympo- sium on Remote Sensing of the Environment, II, Michigan: Ann Arbor 895-934

Wald L, Basly L, Balleynaud JM (1999) Satellite data for the air pollution mapping. Proceedings of the 18th EARseL symposium on operational sensing for sustainable development (Enschede, Netherlands, 11-14 May 1998) edited by Nieeuwenhuis, G.J.A, Vaugham, R.A., Molenaar, M.: 133-139 